\title{
Effect of light on quality of milk
}

\author{
NIHA KHAN AND KARUNESH SAXENA
}

Received: 01.05.2017; Revised: 04.10.2017; Accepted: 18.10.2017

See end of the paper for authors' affiliations

\section{NIHA KHAN}

Pacific Institute of Dairy and Food

Technology, Pacific University, JAIPUR (RAJASTHAN) INDIA
ABSTRACT : Light-exposure is a very much chronicled issue in the investigation of the nature of milk. Milk subjected to light amid transport, handling, and storage can create undesirable off-flavors and fragrances, because of riboflavin prompted breakdown of proteins and lipids. In spite of much review into these marvels, most work to date has been completed with incandescent or fluorescent light sources. The present day production network and retail condition is advancing, and right now the dairy business is seeing numerous providers embracing LED lighting in show cases, basically as a cost sparing and maintainability measure, because of lower running expenses. LED lighting produces a highly modified range of light than the fluorescent frameworks at present supported. The nearness of milk fat seems to ensure against vitamin A debasement in liquid items, however unfavorably influences the flavor nature of milk after presentation to light.

KEY WORDS: Vitamin A, Light oxidation, Fortified milk, LED lights, Light-exposed flavor

- HOW TO CITE THIS PAPER : Khan, Niha and Saxena, Karunesh 2017). Effect of light on quality of milk. Asian J. Home Sci., 12 (2) : 427-431, DOI: 10.15740/HAS/AJHS/12.2/427-431. 